\title{
THE SOCIO-EMOTIONAL EXPERIENCES OF OLDER PERSONS WITH VISUAL IMPAIRMENTS
}

\section{T Meyer, S Green}

\section{INTRODUCTION}

Older persons constitute the fastest growing segment of the population in many nations around the world. The estimation is that by the year 2050 one in every five persons will be 60 years or older (Keigher, Fortune \& Witkin, 2000:xiii). According to Branch, Horowitz and Carr (1989:359) visual impairment is the second most prevalent physical impairment among older persons.

As noted by Horowitz and Reinhardt (1998:30) the onset of visual impairment, for older persons who have been fully sighted their entire lives, is an enormous experience requiring adjustment in psychosocial and functional aspects of their lives. In South Africa, The White Paper for Social Welfare (Ministry for Welfare and Population Development, 1997:78-79) identifies older persons with disabilities, including blindness, as especially vulnerable.

In a community survey conducted by Ferreira, Gillis and Moller (1989:113) in the Western Cape Province of South Africa, 150 persons over the age of 65 years indicated that visual impairment contributed markedly towards their functional incapacity. As a noteworthy lack of recent research (Branch et al., 1989:360; Yeadon, 1991:185;) related to the socio-emotional experience of older persons with visual impairment was confirmed by the Head of the Ophthalmology Department at Tygerberg Hospital in Bellville, South Africa, the need for updated research in this field was identified and permission to conduct this study was granted.

The paper starts with a problem statement followed by a brief discussion of the research methodology. Thereafter the research findings are discussed from the theoretical framework of a life stage approach and the ecological perspective. After a presentation of identifying details of the participants, aspects such as overall health, visual ability and impairment, psycho-social implications of vision loss, and access to support and help are discussed and verified with reference to literature. The paper ends with some conclusions based on the findings of the study and some suggestions for future research.

\section{PROBLEM STATEMENT}

Literature (Crews, 1992:138; Rogers \& Long, 1991:154) confirms the increase in the number of older people and research (Branch et al., 1989:359; Cherry, Keller \& Dudley, 1991:100) validates that the high risk of severe visual impairment increases with age. Furthermore, researchers (Branch et al., 1989:359, Lusakko, Mantyjarvi, Kautiainen \& Sulkava, 2003:573-574; Vaughan \& Hobson, 1990:370) are of the opinion that visual impairment, especially after a lifetime of normal vision, has an intense effect on the quality of life for many older persons contributing to an increase in dependency on others. As Orr and Rogers (2001:670) point out, there is an increased awareness of the growing demand for support services for older people.

\section{RESEARCH METHODOLOGY}

Against the forgoing problem statement, the goal of the research was to gain a better understanding of the socio-emotional experiences of older people with visual impairments. 


\section{CLARIFICATION OF KEY CONCEPTS}

For the aim of this study the following concepts were clarified:

- Older persons (Elderly)

People who are 65 years of age or older.

- Visual impairment

The "...visual inability to read, to watch television or to orientate one-self in unfamiliar surroundings..." (Moenestam \& Wachtmeister, 2002:1087).

- Adjustment/Adaptation to visual impairment/vision loss

Adjustment to visual impairment is defined as the attainment, by visually impaired older persons, of an environment in which they are optimally constructive and minimally incapacitated by their visual impairment (Cambert, West \& Carlin, 1981:193).

The study employed a qualitative research approach and exploratory design to obtain the goal of the research. The population for this study was defined as all the patients, 65 years and older, from the Ophthalmology Outpatients Department at Tygerberg Hospital, Bellville, South Africa who experienced visual impairment, and visited the Department during the month of August 2005. The criteria for inclusion were:

- Male and female patients;

- Older persons over the age of 65 years;

- Older persons who are visually impaired (i.e. the inability to read, watch television or to orientate one-self in unfamiliar surroundings).

On average, 50 patients, that meet the criteria for inclusion of the study, visit the clinic during a month. At the conclusion of the study, the sample consisted of ten participants selected by means of a purposive sampling method (De Vos, Strydom, Fouche \& Delport, 2002:334). Data was collected with a semi-structured interview with the aid of an interview guide (Tutty, Rothery \& Grinnell, 1996:52). All the interviews were audio taped with the permission of the participants. First, the tape-recorded interviews were transcribed. Then data was analysed in the following way: the transcriptions were organised in computer files, read, and then sorted according to categories and themes (Tutty et al., 1996:92). The data is presented in narrative and tabular form.

\section{RESEARCH FINDINGS}

The findings of the study are related to the socio-emotional experiences of older persons with visual impairments and are analysed from a life stage approach and the ecological perspective. After a presentation of identifying details of the participants, the following themes are discussed: overall health; visual ability and impairment; the psycho-social implications of vision loss; and accessing support and help.

\section{Identifying details of participants}

The identifying details of the participants are summarised in Table 1. They varied in terms of age, gender, marital-status, race and socio-economic status. The study only included people from the Coloured and White population groups. 
TABLE 1

IDENTIFYING DETAILS OF PARTICIPANTS

\begin{tabular}{|c|c|c|c|c|c|}
\hline P & Age & Marital Status & Race & Gender & Monthly Income \\
\hline 1 & 65 & Widow & Coloured & Female & R500-R999 \\
\hline 2 & 80 & Widow & White & Female & R500-R999 \\
\hline 3 & 78 & Widow & Coloured & Female & R500-R999 \\
\hline 4 & 73 & Widow & Coloured & Female & R500-R999 \\
\hline 5 & 70 & Maried & White & Male & R1500-R1999 \\
\hline 6 & 69 & Maried & White & Male & R1000-R1499 \\
\hline 7 & 74 & Maried & White & Male & R500-R999 \\
\hline 8 & 75 & Maried & White & Male & R1500-R1999 \\
\hline 9 & 77 & Maried & Coloured & Male & R500-R999 \\
\hline 10 & 66 & Never maried & Coloured & Female & R500-R999 \\
\hline
\end{tabular}

\section{Overall health}

More than half of the participants in the study described their overall health as good. The other participants had other health problems not related to their eyesight: chronic lymphatic leukaemia and diabetes; pneumonia; and emphysema. According to Du Pre (1982:365) these are general health problems for older persons.

\section{Visual ability and impairment}

Six of the participants experienced vision loss within the last ten years. For these older persons, loss of vision was a progressive process over a number of years. The participants expressed their feelings associated with the onset of vision loss as follows:

- "I was very sad. It is not pleasant to become blind."

- "I was upset, yes. My eyes have always been good, why do I have all these problems now that I'm old."

- "It is so... uncomfortable, I feel so helpless. You cannot do anything for yourself."

- "I felt so down."

From the above we can deduce that there is a variety of feelings associated with the onset of vision loss: sad, upset, uncomfortable, helpless, and down.

The participants described their visual functioning at present as poor:

- "Yes, I can see far, but I cannot read. If the letters are small I cannot read them."

- "With this eye I cannot see anything. If I close this eye, I cannot see you."

- "I cannot read telephone pages."

- "Not good."

- "I can see if I look far away, but I cannot see you."

- "When I watch television I think it is dull, but actually it is colourful."

This corresponds with Moenestam and Wachtmeister's (2002:1087) description of visual impairment as the "...visual inability to read, to watch television or to orientate one-self in unfamiliar surroundings...". 


\section{Psycho-social implications of vision loss}

Welch (1987:155-159) is of the opinion that the ecological perspective (Germain \& Gitterman, 1980:77-79) provides an appropriate cognitive framework for social work in general and for the South African context. He developed a model based on this perspective that is still relevant today as the synergetic effect of the interaction between the individual and his/her environment still occurs today (Payne, 2005). The synergetic effect can be compared to throwing a stone in a dam of water and seeing the ripples form outwardly from small to big. The smallest ripple causes a bigger ripple and so on.

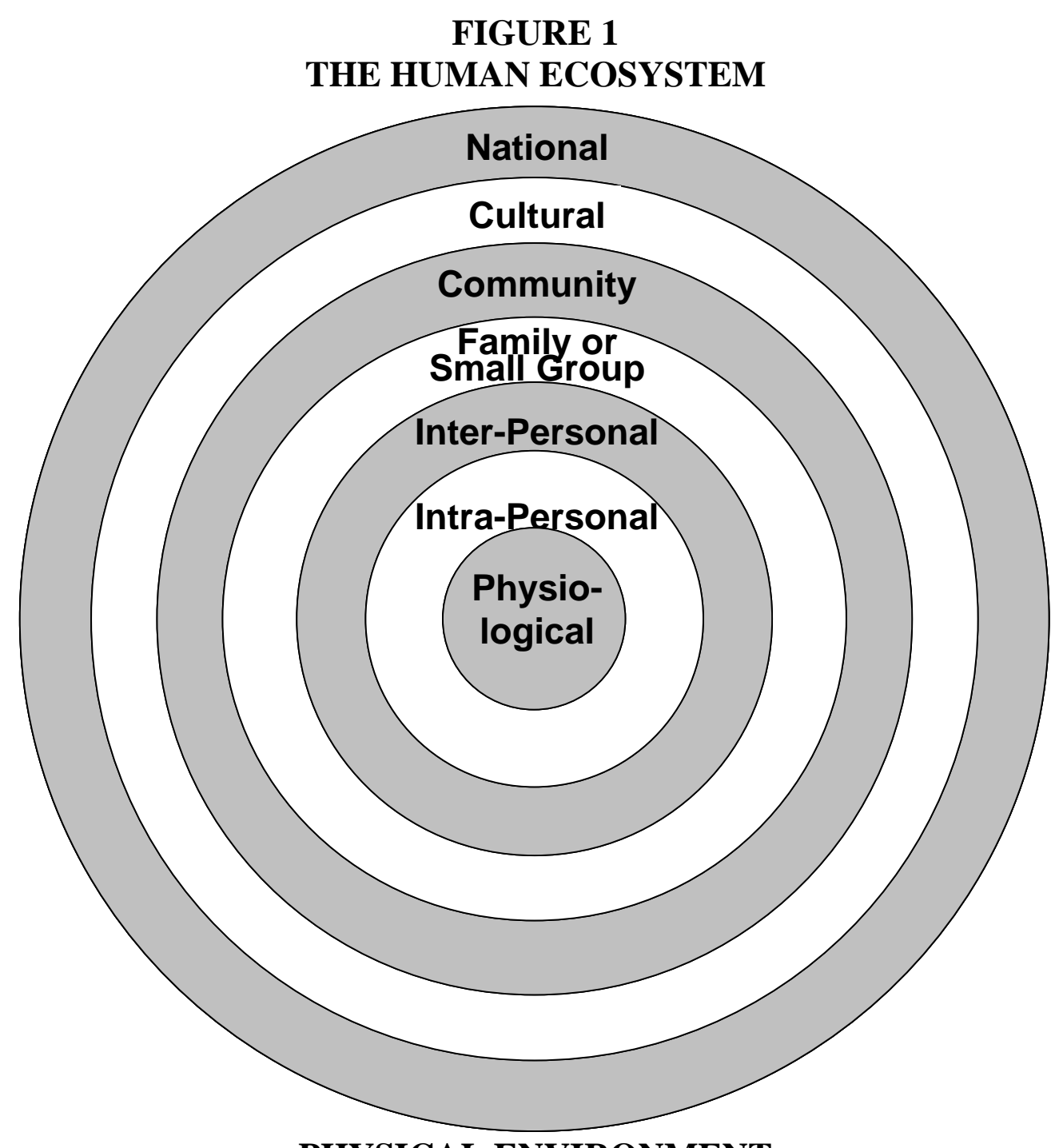

PHYSICAL ENVIRONMENT

(Welch 1987:156)

In his concentric model, Welch $(1987: 156)$ demonstrates the synergetic effect of the interaction between the individual and his/her environment. Each circle represents a level of functioning within the greater human ecosystem. Even though the lines indicating the different levels are solid lines, the borders of the level are permeable to allow interactions between the different levels of the ecosystem and the ecosystems and the physical environment. The levels are intrapersonal, inter-personal, family or small groups, community.

Welch's model is used to explore the socio-emotional experience of older persons with visual impairment. 
On an intra-personal level, literature (Hill \& Harley, 1984:50) indicates that as older persons begin to experience visual impairment, many fears arise as they wonder how it will affect their health and their inability to meet their financial obligations. The psychosocial implications of vision loss include the impact of vision loss on daily activities like: driving, shopping, sport, television, needlework, knitting and reading:

\section{Driving}

- "I feel that I have to drive more carefully than before. When I pass another vehicle I have to make double sure the road is clear."

- "It is so bad that when I drive behind a car I cannot read the registration number."

- "When I drive I have to close my one eye otherwise I see two cars, one in front of me and the other left of me, then I must close my one eye."

- "Now it is effecting my driving. It is like a haze all the time."

This corresponds with literature (Jackson et al., 1983:469) that suggests that older persons who are visually impaired experience greater difficulty when travelling.

\section{Shopping}

According to Inana (1980:329) grocery shopping can prove to be a great challenge for visually impaired individuals.

- "O, it was very bad. My daughter eventually had to shop for me."

- "My son always comes to help, and then he takes met to the shop."

\section{Sport}

One participant explained that visual impairment influenced the ability to take part in sport:

- "It is a little difficult, because I have to throw the ball in a ring, sort of like a netball ring, and I could not see to throw the ball in."

For this respondent, visual impairment limits his/her participation in social activities, and has a negatively influences his/her daily functioning. From literature (Raubenheimer et al., 1998:595596) it is clear that exercise is important in preventing many diseases in old age therefore, not being able to participate in sport activities could in turn have a diverse effect on older persons overall health.

\section{Television}

Two participants made the following comments about the influence of visual impairment on their ability to watch and enjoy television:

- "When I watch television I think it is dull, but actually it is colourful."

- "When I watch the weather report, then it says 10 but I read 110. Or the letters seem to flow into each other so that I cannot read them."

During their free time, many older persons enjoy watching television. However, visual impairments negatively affect their ability to watch television, limiting their ability to enjoy this activity. Furthermore, for many older persons television acts as a source of information like the participant mentioned above that could not watch the weather report anymore. This could lead older persons to become uninterested in the world around them as they cannot gain the needed information as easily as before (Corn, 1983:373-376). 


\section{Needlework and knitting}

One of the activities that many older women are involved in, in old age, is needlework and knitting.

- "I love doing needlework. But eventually I could not see to thread the needle, and my grandson had to help me. Then I did not feel like doing needlework anymore, and it used to be my pleasure in life."

However, with the onset of visual impairment, their ability to do needlework or knit becomes limited and they cannot partake in it as easily as before. Several (30\%) of the participants expressed, that visual impairment influenced their ability to do needlework and knitting:

- "I love knitting, but I could not see what was written on the paper, then I had to call one of the children to tell me."

- "When they do needlework I cannot join in."

\section{Reading}

Half of the participants indicated that visual impairment negatively influenced their ability to read.

- "It was really hard when I realised I cannot read. I love reading."

- "The last month or so I started having trouble reading."

For older persons, reading is often linked to other social activities like going to church. One of the participants still attended church but could not read in her Bible or hymnal.

- "On a Sunday when I am in the church, then I sit with the book upside down, or I am at the wrong hymn."

Reading also forms an important part of older persons' spiritual life as reading the Bible helps older persons grow and develop spiritually. However, some older persons cannot read their Bible anymore and this negatively influences their spiritual development.

- "No, I do not read Bible anymore."

Another participant could not read telephone pages anymore.

- “...but I cannot read telephone pages."

This not only influences the individual personally, but also socially as he/she cannot interact with his/her social environment as easily as before (Corn, 1983:373-376).

On an inter-personal, family or small group/community level of Welsch's Model, literature (Parry \& Young, 1978:56) outlines that interactions among family members are often disrupted due to the onset of disability in one family member. With the onset of visual impairment in older persons, misunderstandings among family members seem to occur regarding the changes in the older persons and his/her feelings regarding the situation (Jacobs, 1984:155). Some of the participants confirmed these suggestions. As the participants note:

- "My family was not really interested and so on..."

- "They were a little uncomfortable with the eye."

- "When I get stressed I'm short tempered."

However, other participants were of the opinion that it did not really influence their relationship with their friends and family negatively, and that their family was very supportive.

- "They were very sympathetic and concerned." 
- "They set my mind at ease."

Authors (Kail \& Cavanaugh, 2000:548; Perlmutter \& Hall, 1992:343; Raubenheimer et al., 1998:642) point out that to many older persons, the most significant phenomenon in life are their relationships with friends and family. Friends and family members can act as a strong support system for older persons with visual impairments.

\section{Accessing support and help}

Participants were mostly unaware of services, other than the hospital, that are available for individuals with visual impairments. Most of the participants were only aware of medical services available at Tygerberg Hospital in order to address their visual impairment.

Yeadon (1991:189-191) points out that many older persons with visual impairments do not have the knowledge or skills concerning their condition. In the study, eight of the participants indicated that having more information regarding the condition and services would make a difference in the experience of vision loss. One participant said: "Awareness like there at the club would help."

Only one respondent was very certain that having more information regarding the condition would make a difference in the experience of vision loss.

- "Yes. But that is as sure as the sun rises in the east and sets in the west. It speaks for itself."

Kalafat and Dehmer (1993:112) proposed that self-help groups are particularly appropriate to address the need for services for older persons with visual impairments because of these provide help for chronic difficulties and emphasise mutual support and the importance of personal experience and strength, instead of dependence and pathology. Several findings suggest that active membership in groups is associated with enhanced satisfaction and coping (Kalafat \& Dehmer, 1993:112).

Half of the participants agreed that participation in a group would make a difference in the experience of vision loss, some of their responses included:

- "Yes, to talk with others about it."

- "Yes. That would help to encourage them. Some people are scared. Maybe scared they will go blind. The one that can easily talk about the thing that makes him sick. Not everyone can...."

- "Yes. I think it would help. For the support."

Two participants indicated that they did not think it would help to be part of a support group:

- "No, not really."

- "No way, I do not feel like listening to other people's nonsense."

Participants thought social workers could help people to adjust easier to visual impairment in the following ways:

- "You could talk to the people."

- "Probably to find out what their needs are."

- "Yes, I think... to help others when they can not see. There are certainly many methods to help those people to be happy."

- "I think to ask them."

- "It would help to go to an Old Age Home and see how you could help there."

They generally suggested that social workers could talk to older persons and find out what they need. 
From an ecological perspective, it is clear that visual impairment does not only affect the individual but also those who care for and about the older person. This is not an isolated event, but one that concerns family, support systems and social structures (Crews, 1991:138). With the detection of visual impairment, the individual and family members experience changes in family life, relationships, work, recreation and finances. As mentioned before, Welch (1987:156) outlines the synergetic effect of changes for an individual. From this study, the synergetic effect of visual impairment on the individual is clear as we note the impact on not only the individual, but also on the family and social structures. In return, the environment also influences the experience of the individual. Finding a goodness-of-fit between the two is the ideal goal of the ecological perspective. In order to balance this equation, social workers need to meet the needs of individuals with visual impairment by rendering support services.

\section{CONCLUSIONS AND RECOMMENDATIONS}

In order to facilitate the adjustment process to changes in vision, Asch (1995:2461-2467) notes that there is a need for social workers to render multi-dimensional services to older persons and their families in order to ensure optimal social functioning. From this exploration into the socioemotional experience of older persons with visual impairments, it would appear that social work interventions should focus on various aspects.

First, the aim of preventative services should be to focus on adults and older persons. These could include placing information in reception rooms at day-hospitals or eye clinics and ensuring that hospital personnel are informed.

Second, services should include: thorough assessment of:

- the impact of chronic illnesses on the daily functioning of older persons in conjunction with the impact of visual impairment;

- the feelings of older persons with visual impairments;

- concerns of older persons regarding their visual impairment;

- potential effects of visual impairment on the older person's relationships with friends and/or family;

- $\quad$ supportive networks;

- psychosocial implications of visual impairment for older persons with visual impairments;

- and older persons' awareness of available service.

Finally, possible social work interventions should include individual and family counselling; informative and teaching services and support groups.

It is suggested that future research focus on the development of social work programmes that increases awareness among social workers regarding older persons with visual impairments and specifically addresses this issues, for example in Rest Homes.

\section{REFERENCES}

ASCH, A. 1995. Visual impairment and blindness. In: EDWARDS, R.L. (Editor-in-Chief). Encyclopaedia of Social Work $\left(19^{\text {th }}\right.$ ed). Washington, DC: National Association of Social Workers Press.

BRANCH, L.G., HOROWITZ, A. \& CARR, C. 1989. The implications of everyday life of incident self-reported visual decline among people over age 65 living in the community. The Gerontologist, 29(3):359-365. 
CAMBERT, R.M., WEST, M. \& CARLIN, K. 1981. Psychology of adjustment to visual deficiency: A conceptual model. Journal of Visual Impairment and Blindness, 75(5):193-196.

CORN, A.L. 1983. Visual function: A theoretical model for individuals with low vision. Journal of Visual Impairment and Blindness, 77(8):373-377.

DU PRE, E. 1982. The agency administrator's role in meeting the needs of the multiply handicapped blind client. Journal of Visual Impairment and Blindness, 76(9):365-367.

CHERRY, K.E., KELLER, M.J. \& DIDLEY, W.N. 1991. A needs assessment of persons with visual impairments: Implications for older adults and service providers. Journal of Gerontological Social Work, 17(3/4):99-123.

CREWS, J.E. 1991. Measuring rehabilitation outcomes and the public polices on aging and blindness. Journal of Gerontological Social Work, 17(3/4):137-151.

DE VOS, A.S. (ed), STRYDOM, H., FOUCHÉ, C.B. \& DELPORT, C.S.L. 2002. Research at grass roots - for the social sciences and human service professions $\left(2^{\text {nd }}\right.$ ed). Pretoria: Van Schaik Publishers.

FERREIRA, M., GILliS, L.S. \& MOLLER, V. (eds) 1989. Ageing in South Africa. Social research papers. Pretoria: Human Sciences Research Council.

GERMAIN, C.B. \& GITTERMAN, A. 1980. The life model of social work practice. New York: Columbia University Press.

HILL, M.M. \& HARLEY, R.K. 1984. Orientations and mobility for aged visually impaired persons. Journal of Visual Impairment and Blindness, 78(2):49-54.

HOROWITZ, A. \& REINHARDT, J.P. 1998. Development of the adaptation to age-related vision loss scale. Journal of Visual Impairment and Blindness, 92(1):30-41.

JACOBS, P.L. 1984. The older visually impaired person: A vital link in the family and the community. Journal of Visual Impairment and Blindness, 78(4):154-162.

KAIL, R.V., \& CAVANAUGH, J.C. 2000. Human development: A lifespan view $\left(2^{\text {nd }}\right.$ ed). Belmont, CA: Wadsworth/Thomson Learning.

KALAFAT, J. \& DEHMER, J. 1993. A survey of statewide self-help groups for older persons who are visually impaired. Journal of Visual Impairment and Blindness, 87(4):112-114.

KEIGHER, S.M., FORTUNE, A.E. \& WITKIN, S.C. (eds) 2000. Aging and social work: The changing landscapes. Washington, DC: National Association of Social Workers Press.

LUSAKKO, T.A., MANTYJARVI, M.I., KAUTIANINEN, H.J. \& SULKAVA, R.O. 2003. Decrease of functional or cognitive capacity explains the lack of eye examination in visually impaired older persons. Journal of American Geriatrics Society, 51(4):573-574.

MINISTRY FOR WELFARE AND POPULATION DEVELOPMENT. 1997. White Paper for Social Welfare. Pretoria: Government Publishers.

MOENESTAM, E. \& WACHTMEISTER, L. 2002. Change of subjective visual function in firsteye cataract patients when the rate of surgery increases in a population. Medical Care, 40(11):1080-1089.

ORR, A.L. \& ROGERS, P. 2001. Development of vision rehabilitation services of older people who are visually impaired: A historical perspective. Journal of Visual Impairment and Blindness, 95(11):669-689. 
PARRY, J.K. \& YOUNG, A.K. 1978. The family as a system in hospital-based social work. Health and Social Work, 3(2):55-69.

PAYNE, M. 2005. Modern social work theory ( $3^{\text {rd }}$ ed). Houndmills: Palgrave Macmillan.

PERLMUTTER, M. \& HALL, E. 1992. Adult development and aging ( $2^{\text {nd }}$ ed). New York: John Wiley \& Sons, Inc.

RAUBENHEIMER, J.R., LOUW, D.A., VAN EDE, D.M. \& LOUW, A.E. 1998. In: LOUW, D.A., VAN EDE, D.M. \& LOUW, A.E. Human development $\left(2^{\text {nd }}\right.$ ed). Kagiso Tertiary.

ROGERS, P. \& LONG, R.G. 1991. The challenge of establishing a national service program for older blind persons. Journal of Gerontological Social Work, 17(3/4):153-163.

STUEN, C. 1991. Awareness of resources for visually impaired older adults among the ageing network. Journal for Gerontological Social Work, 17(3/4):165-179.

TUTTY, L.M., ROTHERY, M.A., \& GRINNELL, R.M. 1996. Qualitative research for social workers. New York: Allyn and Bacon.

VAUGHAN, C.E. \& HOBSON, S. 1990. Reducing late-lide dependence resulting form declining visual acuity. Journal of Visual Impairment and Blindness, 84(7):370-372.

WELCH, G.J. 1987. An integrated approach to social work practice. In: McKENDRICK, B.W. (ed) Introduction to Social Work in South Africa. Pinetown: Owen Burgess Publishers.

YEADON, A. 1991. 'Far too little, far too low': Toward a new and immediate strategy of rehabilitation for the elderly visually handicapped. Journal of Gerontological Social Work, 17(3/4):181-196.

Tania Meyer, Masters student, Department of Social Work, Stellenbosch University; Prof Sulina Green, Department of Social Work, Stellenbosch University, Stellenbosch, South Africa. 